\title{
Research on City Fire Station Layout Optimization Based on LINGO
}

\author{
Zhang Limin \\ Chinese People's Armed Police Force Academy, LangFang, HeBei, China \\ Zhang_lim@163.com
}

Keywords: city; fire station; layout; optimization; LINGO

\begin{abstract}
Based on the analysis of city fire station layout influencing factors, this thesis studied of common fire station layout optimization method and model, finally brought forward the advantage of LINGO and studied a certain city fire station layout by using LINGO, in the hope of providing some reference for city fire station layout planning, making the new construction, renovation and expansion of the city fire station more reasonable, enhancing the city's ability to resist fire risk and ensuring people's life and property safety.
\end{abstract}

\section{Introduction}

As an important city infrastructure, city fire station provide security guarantee for normal economic and social activities. Reasonable fire station layout has very important significance to ensure the rescue effect of fire fighting and enhance the ability of city disaster prevention. Although the research personnel of domestic and foreign have some beneficial attempt on the fire station layout optimization problems, but still inadequate, arranging fire station more reasonable has become an inevitable topic in the city modernization.

\section{Influence Factors of City Fire Station Layout}

Fire station layout optimization is influenced by many factors, the influence degree of each factor on the decision is different, different regions should establish fire station by the actual situation. The main factors which influence the fire station layout are as following:

\section{A. Time Factors}

Fire suppression has certain time constraints, so the time is an important factor which affects the fire station layout. At present, according to China's fire station construction standards, " 15 minutes fire time" is often used as the basic principle of fire station layout. The purpose that the fire station is located in the proper location of the jurisdiction area is that when the farthest point break out of fire, the fire brigade can rush to the fire scene as soon as possible.

\section{B. Economic Factors}

As a part of city overall planning, the role of fire station is influenced by economic factors. Considering from the angle of economy, the number of fire stations is as less as better, in order to maintain the lowest construction cost and maximum service efficiency. Different areas have different economic levels, land price, and commodity price, which influence the construction and operation input of fire station. How to arrange the fire stations scientifically and reasonably according to the budget is the problem which should be considered in fire station optimization model.

\section{Traffic Factors}

Traffic network is one of the key factors influencing the effectiveness of fire fighting and rescue. Traffic conditions limit include vehicle access roads or sections limit, one-way traffic limit and transit time limit. The fire station should be located in the adjacent street where the vehicle can dispatch conveniently and quickly, such as road cross section or one side of the main streets.

\section{Commonly Used Fire Station Layout Optimization Model}

\section{A. Shortest Travel Distance Model}

This model optimize spatial location of the fire station in all candidate fire station layout scheme 
according to the given number, so that the sum of the distances of all the fire demand point to the nearest fire station is the shortest, the practical significance is to make the trip distance minimization.

Because the ultimate goal of this model is make the total trip distance shortest, thus inevitably sacrifice few users of remote location.

\section{B. Maximum Coverage Model}

This model pick out the spatial position of a given number of facilities in all candidate facility location and make the most facilities demand point within the maximum radius of service facilities.

In the application of this model, some demand points may still be outside of facility coverage range, this is very disadvantageous to emergency rescue.

\section{Integer Linear Programming Model}

Linear programming model is one of the most basic and the most simple one of all the programming model, it takes maximum or minimum value of a linear function as the target under the constraints of a set of linear equations or inequalities. 0-1 integer linear programming is a special form of integer programming, it requires the values of the decision variables must be 0 or 1 . There is a wide application of $0-1$ programming in the factory location, transport, investment, and the development of new products, that provide scientific basis for management decision. The LINGO is an effective tool for integer programming problems, using the software, linear programming model can be solved, then the optimization problem can be solved too.

\section{LINGO Software}

LINGO, namely "linear interactive and general optimizer", is an effective tool for solving linear, nonlinear, integer programming, two programming and linear, nonlinear equations and other optimization problems.

A. Characteristics of LINGO

- For large-scale mathematical programming, LINGO language model expresses simple. LINGO can express linear, nonlinear and integer programming problem by understandable mathematical formulas, require no special programming language, and the program is easy to read and modify.

- The input and output of date select easily. To the solving model LINGO can directly read the relevant data from the other database or spreadsheet, save a large amount of data input time and save manpower. At the same time, the data initialization part and the other part is separated, for the same model, when calculate with different data, only need to change the objective function and constraint conditions.

- LINGO can solve a variety of programming problems. The built-in solver can solve linear, nonlinear, two times, two time constraints and integer optimization problem, can also solve the multi constraint variables and target problem, which is applicable to a variety of optimization problems.

B. Solving Steps of LINGO

- Establish mathematical model which is need to solve according to the practical problems, that is to say, establish the objective function and realize the maximum or minimum of target function in the constraint conditions.

- Analyze decision variables of the mathematical model and give constraint conditions according to the research contents, these constraint conditions are expressed by a set of linear or nonlinear equations or inequalities. In the control of these constraint conditions, target function can achieve optimal value.

- Select the appropriate solution model, prepare the source code, solve the established model by using LINGO and analyze of the results.

\section{Optimization Examples of City Fire Station Layout based on LINGO}

Taking a certain city as an example, the optimal model is established by using $0-1$ integer linear programming method, and then solve the model by using LINGO.

A. Data Acquisition 
The Zones distribution of a city is shown as Figure 1, prepare to relocate fire station in six zones of this city, hope to establish minimum fire stations to ensure that each zone has at least one fire brigade can arrive in 5 minutes, and at the same time the construction cost is minimum. The distance between each zones are shown in Table 1,the costs of building fire station also are not identical in six zones, respectively (unit: million Yuan): 10, 18, 15, 13.5, 16, 13, try to establish the optimization model. For the convenience of modeling, not considering the traffic capacity of the road and the road winding coefficient, the distance between zone and zone refers to the distance between the zone center.

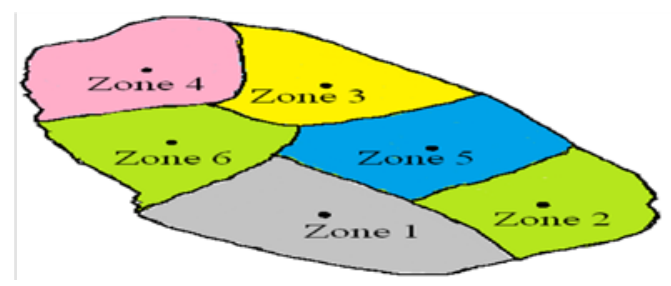

Figure 1. Zone Range Chart

Table 1. Distance Between Zones

\begin{tabular}{|c|c|c|c|c|c|c|c|}
\hline \multicolumn{2}{|c|}{} & \multicolumn{7}{|c|}{ End Point } \\
\cline { 3 - 9 } Distance $(\mathrm{Km})$ & $\begin{array}{c}\text { Zone } \\
1\end{array}$ & $\begin{array}{c}\text { Zone } \\
2\end{array}$ & $\begin{array}{c}\text { Zone } \\
3\end{array}$ & $\begin{array}{c}\text { Zone } \\
4\end{array}$ & $\begin{array}{c}\text { Zone } \\
5\end{array}$ & $\begin{array}{c}\text { Zone } \\
6\end{array}$ \\
\hline \multirow{4}{*}{$\begin{array}{c}\text { Starting } \\
\text { Point }\end{array}$} & Zone 1 & 0 & 3 & 7 & 10 & 10 & 7 \\
\cline { 2 - 9 } & Zone 2 & 3 & 0 & 8 & 12 & 7 & 3 \\
\cline { 2 - 9 } & Zone 3 & 7 & 8 & 0 & 5 & 10 & 7 \\
\cline { 2 - 9 } & Zone 4 & 10 & 12 & 5 & 0 & 5 & 8 \\
\cline { 2 - 9 } & Zone 5 & 10 & 7 & 10 & 5 & 0 & 4 \\
\cline { 2 - 9 } & Zone 6 & 7 & 3 & 7 & 8 & 4 & 0 \\
\hline
\end{tabular}

\section{B. Establish Optimization Model}

The location decision problems of fire station can be solved by integer programming mathematical model and using $0-1$ integer programming, the basic form of $0-1$ planning is as follows:

$$
\begin{aligned}
& \min Z=\sum_{i=1}^{n} c_{i} x_{i} \\
& \left\{\begin{array}{l}
\sum_{i=1}^{m} a_{i} x_{i} \leq b_{i} \\
x_{i}=0 \text { or } 1
\end{array}\right.
\end{aligned}
$$

\section{Analysis the Results of Model}

Suppose that the fire truck in this city drive 60 kilometers per hour, convert Table 1 into distance expressed by time, so as to facilitate the list of constraints, which is shown in Table 2.

According to Table 2, lists the decision variable and objective function

The decision variable is:

$X_{1}\left\{\begin{array}{l}1 \text {, If the fire station built in this zone } \\ 0, \text { If the fire station doesn't built in this zone }\end{array}\right.$ 
Table 2. Required Time Between Zones

\begin{tabular}{|c|c|c|c|c|c|c|c|}
\hline \multicolumn{2}{|c|}{} & \multicolumn{7}{|c|}{ End Point } \\
\cline { 3 - 9 } \multicolumn{2}{|c|}{ Time $(\min )$} & $\begin{array}{c}\text { Zone } \\
1\end{array}$ & $\begin{array}{c}\text { Zone } \\
2\end{array}$ & $\begin{array}{c}\text { Zone } \\
3\end{array}$ & $\begin{array}{c}\text { Zone } \\
4\end{array}$ & $\begin{array}{c}\text { Zone } \\
5\end{array}$ & $\begin{array}{c}\text { Zone } \\
6\end{array}$ \\
\hline \multirow{4}{*}{$\begin{array}{c}\text { Starting } \\
\text { Point }\end{array}$} & Zone 1 & 0 & 3 & 7 & 10 & 10 & 7 \\
\cline { 2 - 9 } & Zone 2 & 3 & 0 & 8 & 12 & 7 & 3 \\
\cline { 2 - 9 } & Zone 3 & 7 & 8 & 0 & 5 & 10 & 7 \\
\cline { 2 - 9 } & Zone 4 & 10 & 12 & 5 & 0 & 5 & 8 \\
\cline { 2 - 9 } & Zone 5 & 10 & 7 & 10 & 5 & 0 & 4 \\
\cline { 2 - 9 } & Zone 6 & 7 & 3 & 7 & 8 & 4 & 0 \\
\hline
\end{tabular}

The objective function is:

Min $=10 X_{1}+18 X_{2}+15 X_{3}+14 X_{4}+16 X_{5}+13 X_{6}$

From Table 2, the zones obeying the constraints which the drive time among the different zones is 5 minutes can be counted, as shown in Table 3.

Table 3. Obeying Constraints Zones

\begin{tabular}{|c|c|c|}
\hline & Zones In 5 Minutes Drive & Constraints \\
\hline Zone 1 & Zone 1, Zone 2 & $x_{1}+x_{2} \geq 1$ \\
\hline Zone 2 & Zone 1, Zone 2, Zone 6 & $x_{1}+x_{2}+x_{6} \geq 1$ \\
\hline Zone 3 & Zone 3, Zone 4 & $x_{3}+x_{4} \geq 1$ \\
\hline Zone 4 & Zone 3, Zone 4, Zone 5 & $x_{3}+x_{4}+x_{5} \geq 1$ \\
\hline Zone 5 & Zone 4, Zone 5, Zone 6 & $x_{4}+x_{5}+x_{6} \geq 1$ \\
\hline Zone 6 & Zone 2, Zone 5, Zone 6 & $x_{2}+x_{5}+x_{6} \geq 1$ \\
\hline
\end{tabular}

In Table 3, $\mathrm{X}_{1}+\mathrm{X}_{2} \geq 1$ expressed that one fire station must be built at least in Zone1 and Zone 2, it ensured that once Zone1 brought out a fire, there must arrive a fire brigade in 5 minutes, the significance of the other inequalities is similar. Thus mathematical model can be established as follows:

$$
\text { Min }=10 x_{1}+18 x_{2}+15 x_{3}+14 x_{4}+16 x_{5}+13 x_{6}
$$

$$
\left\{\begin{array}{l}
x_{1}+x_{2} \geq 1 \\
x_{1}+x_{2}+x_{6} \geq 1 \\
x_{3}+x_{4} \geq 1 \\
x_{3}+x_{4}+x_{5} \geq 1 \\
x_{4}+x_{5}+x_{6} \geq 1 \\
x_{2}+x_{5}+x_{6} \geq 1 \\
x_{i}=0 \text { or } 1, \quad i=1,2, \cdots, 6
\end{array}\right.
$$

Solve the problem by LINGO, the program is shown in Figure 2: 


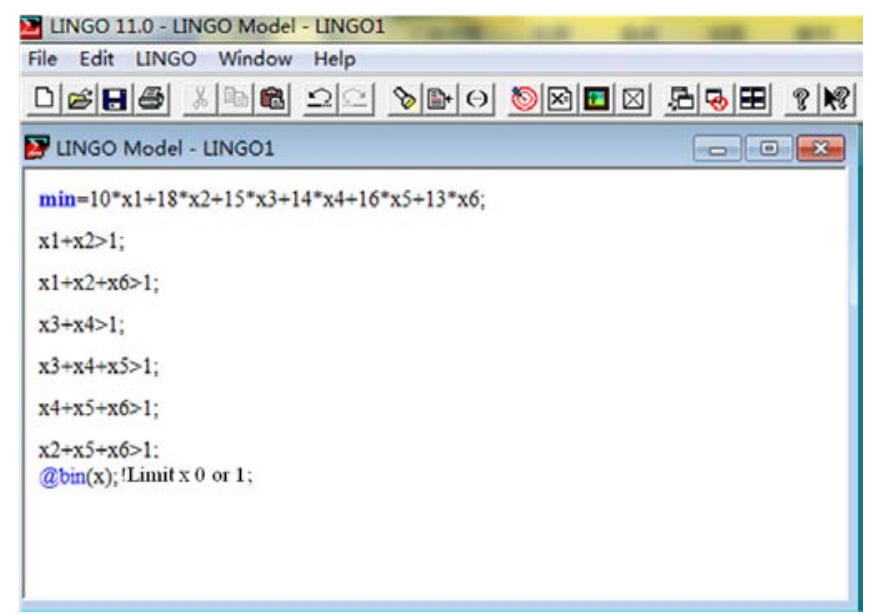

Figure 2. The source program of LINGO

The running results of LINGO is shown as Figure 3, "Objective value: 32.00000" express optimal objective value, it is said that the lowest construction cost to meet the city fire station construction of 5 minutes is 320 Million Yuan. "Value" give the value of each variable in optimal solutions, the value of $\mathrm{X}_{2}$ and $\mathrm{X}_{4}$ is 1 , it expressed that fire station must be built in Zone 2 and Zone 4, as shown in Figure 4.

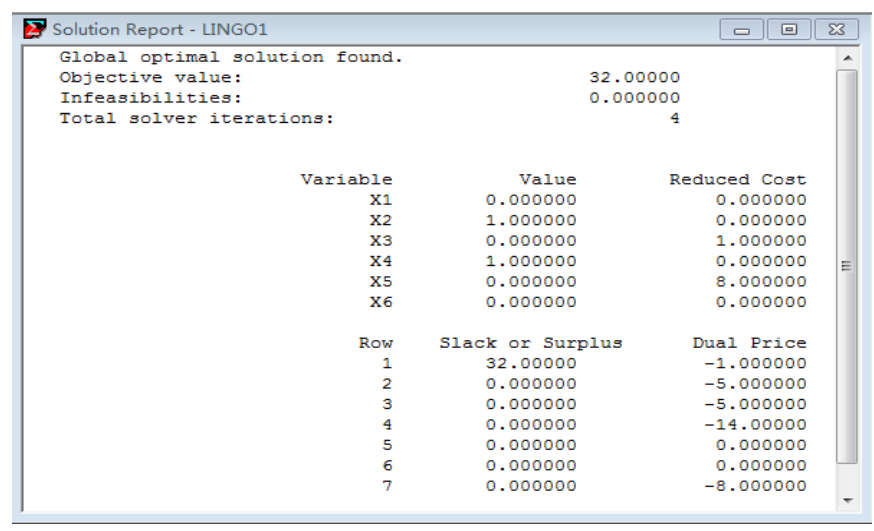

Figure 3. The results of the application of LINGO

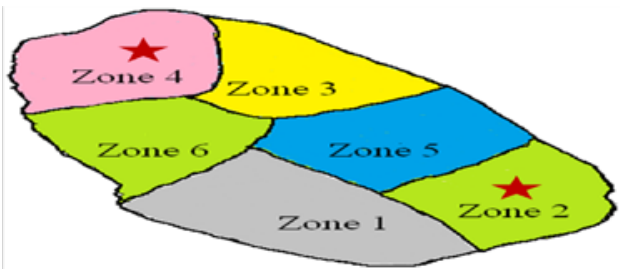

Figure 4. Fire Station Construction

\section{Conclusion}

Fire stations location optimization result is given by LINGO quickly and accurately in this paper, that is to say that in Zone 2 and Zone 4 fire station should be built, but the paper does not have a study on fire station specific location, when determine the specific location, city economic development and city planning shall be considered. Through the analysis of examples, we can see that LINGO is more convenient and more practical compared to other software in solving practical optimization problems. Researching on city fire station layout by using LINGO can provide certain reference function for city fire station layout planning, then enhance the ability to resist the city fire risk, ensure people's safety of life and property. 


\section{References}

[1] Zhang_hanqing,Dai_shenzhi.A review of city safety plan research [J]. City Planning Forum,2005,156(2):38-44.

[2] FengKai,Xue_zhisheng,Yang_shujiang. Study on the fire station layout plan and visualization system [D]. Fire science and technology,2006,25(1):97-99.

[3] Xie_jinxing,Xueyi.Optimization modeling and LINDO/LINGO [M].BeiJing: Tsinghua University press,2005.7.

[4] Yuan_Xinsheng,Shao_dahong,Yu_Shilian. Application of LINGO and Excel in mathematical model [M].BeiJing: Science Press, 2007.

[5] Ministry of Public Security. City fire station construction standards (standard 152-2011) [S].

Beijing: China planning Press, 2011.10. 